\title{
IOP Variations in the Sitting and Supine Positions
}

\author{
Jorge Jorge, PhD, Rui Ramoa-Marques, OD, Adelaide Lourenço, OD, Sandra Silva, OD, \\ Sérgio Nascimento, PhD, António Queirós, OD, and José M. Gonzalez-Méijome, PhD
}

\begin{abstract}
Purpose: The aim of this study was to assess the influence of the position (upright vs. supine) in the intraocular pressure (IOP) measured with a non-contact portable tonometer.
\end{abstract}

Methods: Fifty university students with a mean age of $22.3 \pm 4.2$ years (mean $\pm \mathrm{SD}$ ) were recruited to participate in this study. IOP was measured with the non-contact tonometer Keeler, Pulsair EasyEye. Measurements in upright and supine positions were randomly obtained. In the upright position, 2 series of 3 measures (UP1 and UP2) and a series of 3 measures in the supine position were performed.

Results: The values obtained in the positions UP1 and UP2 were compared, as well as the values of the upright and supine positions. No statistically significant differences were found when comparing the values obtained in the upright position $(P>0.05)$. Instead, when the subjects were in the supine position, IOP increased $2.47 \pm 2.12 \mathrm{~mm} \mathrm{Hg}$ (mean $\pm \mathrm{SD})$, as opposed to the value obtained in the upright position $(P<0.001)$.

Conclusions: Results from this study showed that IOP increased when measured in the supine position and that the Pulsair EasyEye tonometer can determine those variations in a healthy young population.

Key Words: intraocular pressure, Pulsair EasyEye, supine position, upright position, non-contact tonometry

( J Glaucoma 2010;19:609-612)

ntraocular pressure (IOP) is essential to maintain the eye structure and physiology. In several conditions, IOP may rapidly change. Numerous studies in the last decades have shown that IOP in humans undergoes circadian variations, with higher peaks in the morning and lower ones in the afternoon and evening. ${ }^{1-3}$

It is also well known that IOP varies with the body position. IOPs have been reported to be higher when the patient's body is in the supine position (SUP) than in the upright position (UP). ${ }^{4,5}$ In the UP, the eye is approximately $30 \mathrm{~cm}$ higher than the heart; however, when the patient is in the SUP, the eye and the heart are at the same level. This difference in height is thought to affect the episcleral venous pressure. ${ }^{6-9}$ The increase of resistance in the aqueous out-flow is probably the cause for the IOP increase in the SUP. ${ }^{10}$

Received for publication April 20, 2009; accepted November 10, 2009. From the Clinical and Experimental Optometry Research Lab, Department of Physics (Optometry), School of Sciences, University of Minho, Braga, Portugal.

Reprints: Jorge Jorge, PhD, Departamento de Física, Universidade do Minho, Campus de Gualtar, 4710 Braga, Portugal (e-mail: jorge@ fisica.uminho.pt).

Copyright (C) 2010 by Lippincott Williams \& Wilkins

DOI:10.1097/IJG.0b013e3181ca7ca5
The IOP measurement in the SUP is important in several situations, such as the establishment of a real circadian curve. Patients with glaucoma, who during the SUP (one-third of their life) experience a considerable increase of IOP, may notice a worsening of their ocular condition because of the higher risk of neural damage. ${ }^{11}$ Another situation of interest is related to bedridden people as they are temporarily or permanently confined to a SUP. In practice, these patients do not have their eyes regularly checked, and the position-related increase in IOP might increase the risk of ocular damage. ${ }^{12}$ The problem here arises from the difficulties in measuring IOP with certain instruments that require a seated position. Portable noncontact tonometer (NCT) can overcome these difficulties even in the hand of nonmedical staff, thus increasing the probability for those patients to be screened regularly.

Another aspect, not frequently mentioned by optometrists and ophthalmologists, is related to the significant variation of IOP during surgical procedures when the patient is under anesthetic, whether he is in the SUP or in the prone position. ${ }^{13,14}$

The purpose of this article is to quantify the IOP variation between the UP and SUP within a population of young adults using a portable NCT.

\section{METHODS}

Fifty eyes from an equal number of university students (11 male and 39 female), with ages ranging from 18 to 34 years $(22.3 \pm 4.2 \mathrm{y}$; mean $\pm \mathrm{SD})$, were recruited for this study. All subjects were free of ocular disease, had no complaints regarding excessive lachrymation, were not taking any medication, and had good health. The study protocol was reviewed by the Scientific Committee of the Faculty of Science at the University of Minho (Portugal). After all procedures were explained, the subjects signed an informed consent form before being enrolled in the study.

An experienced optometrist evaluated IOP with the air-puff tonometer Pulsair EasyEye (Keeler Instruments, Inc, Broomall, PA.) In each eye, 2 series of 3 measurements in the UP were performed (UP1 and UP2) and 1 series of 3 measures in the SUP. Three different orders of measurements were established (UP1-UP2-SUP or UP1-SUP-UP2 or SUP-UP1-UP2) and they were carried out in a random order. The measurements were performed after the subject was in the position to be measured (UP or SUP) for 15 minutes. All measurements were taken between 14:00 and 16:00 hours to minimize the effect of diurnal variations in IOP.

The values obtained in the position UP1 and UP2 were compared, to analyze the repeatability of the Pulsair EasyEye tonometer. To obtain the variation between the UP and SUP, the values obtained in the SUP were 
TABLE 1. The Mean Values and the SD, the Maximum and Minimum, the Mean Difference, the Level of Statistical Significance, and the Limits of Agreement Between Each Pair of Measured Situations (UP1 vs. UP2 and UPm vs. SUP)

\begin{tabular}{|c|c|c|c|c|c|c|}
\hline \multirow[b]{2}{*}{$\mathbf{N}=\mathbf{5 0}$} & \multirow[b]{2}{*}{ Mean \pm SD } & \multirow[b]{2}{*}{ Minimum; Maximum } & \multirow[b]{2}{*}{ Mean Difference } & \multirow[b]{2}{*}{$\boldsymbol{P}$} & \multicolumn{2}{|c|}{ Limits of Agreement } \\
\hline & & & & & Mean $-1.96 \times$ SD & Mean $+1.96 \times$ SD \\
\hline UP 1 & $12.0 \pm 2.55$ & $8.0 ; 20.0$ & $0.5 \pm 1.99$ & 0.082 & -3.40 & 4.40 \\
\hline UP 2 & $11.5 \pm 2.78$ & $7.0 ; 17.0$ & & & & \\
\hline UPm & $11.8 \pm 2.47$ & $7.5 ; 18.0$ & $-2.47 \pm 2.12$ & $<0.001$ & -6.63 & 1.69 \\
\hline SUP & $14.2 \pm 3.25$ & $8.0 ; 24.0$ & & & & \\
\hline
\end{tabular}

Wilcoxon Signed Ranks Test.

SUP indicates supine; UP, upright; UPm, upright mean.

compared with the average of the 2 measurements series obtained in the UP $[\mathrm{UPm}=(\mathrm{UP} 1+\mathrm{UP} 2) / 2]$.

In this study, data were analyzed using the statistical package SPSS v.17.0. The bias was statistically assessed as the mean of the differences compared with zero. The hypothesis of zero bias was examined by the nonparametric Wilcoxon signed ranks test. The $95 \%$ limits of agreement (mean of the difference $\pm 1.96 \times \mathrm{SD}$ of the differences) were also calculated, as recommended by Bland and Altman. ${ }^{15,16}$ This analysis allows the detection of any trend in the difference variability as a function of the mean value to be measured.

\section{RESULTS}

We collected data from both eyes and found results between right and left eyes to be highly correlated. Therefore, we opted to report data from left eyes only in this report.

Table 1 displays the mean and SD of IOP measurements in both positions. The mean difference and the level of statistical significance are also present, as well as the limits of agreement between each pair of measured situations (UP vs. UP2 and UPm vs. SUP) to be compared at the $95 \%$ confidence interval.

These values reflect a significant increase of the IOP value in the SUP. The difference obtained in the 2 series of measurements performed with the subjects in the UP was as small as $0.50 \mathrm{~mm} \mathrm{Hg}$, not being statistically significant $(P=0.082)$. In contrast, the mean difference of measurements obtained in the UP and SUPs was of $2.47 \mathrm{~mm} \mathrm{Hg}$ higher in the SUP, being statistically significant $(P<0.001)$.

Figure 1 displays the sets of differences as an average function to graphically illustrate the agreement between measurements obtained in both positions (UP and SUP). In Figure 1B, the graphic points out that, when IOP increases, the difference in the values obtained in the SUP also increase.

Figure 2 presents the percentage of subjects with mean differences between the 2 positions of $\leq 1 \mathrm{~mm} \mathrm{Hg}(\leq 1)$, between 1 and $2 \mathrm{~mm} \mathrm{Hg}(>1$ and $\leq 2)$, between 2 and $3 \mathrm{~mm} \mathrm{Hg}$ ( $>2$ and $\leq 3$ ), and $>3 \mathrm{~mm} \mathrm{Hg}$. In $50 \%$ of the subjects, the difference between the 2 series of measurements in the UP (UP1 vs. UP2) was $\leq 1 \mathrm{~mm} \mathrm{Hg}$ and in $92 \%$ of the subjects, the difference was $\leq 3 \mathrm{~mm} \mathrm{Hg}$.

When comparing the results obtained in the UP and SUPs (UPm vs. SUP), it is remarkable that only $20 \%$ of the subjects present a difference of $\leq 1 \mathrm{~mm} \mathrm{Hg}$, whereas in $36 \%$ of the subjects the difference is higher than $3 \mathrm{~mm} \mathrm{Hg}$.

\section{DISCUSSION}

There are few tonometers capable of measuring IOP in the SUP or in the prone position. The Model 30 pneumotonometer, the digital tonometer TGDc-01, the Pulsair EasyEye, the Perkins, and the hand-held Schiotz tonometers are able to obtain IOP values in other positions besides the upright one.
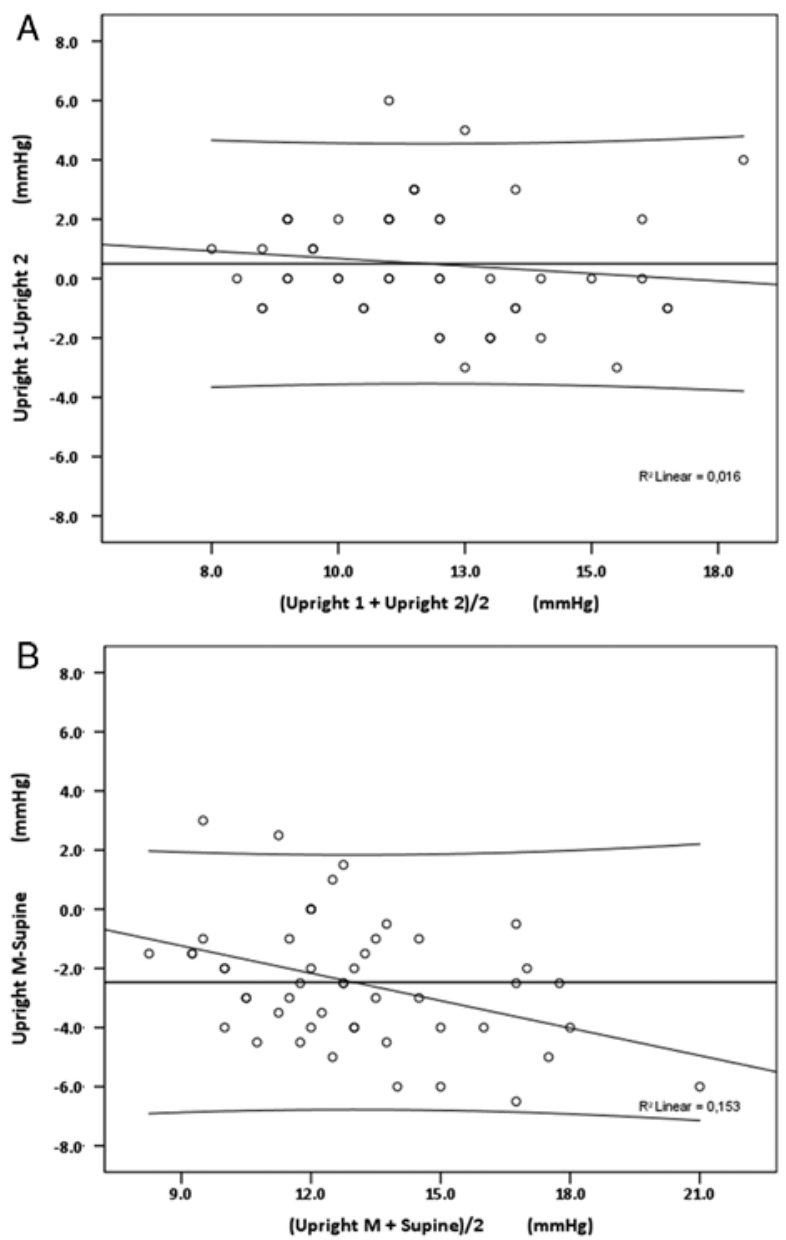

FIGURE 1. Sets of differences as an average function obtained in both positions: (A) upright position; (B) upright and supine position. 

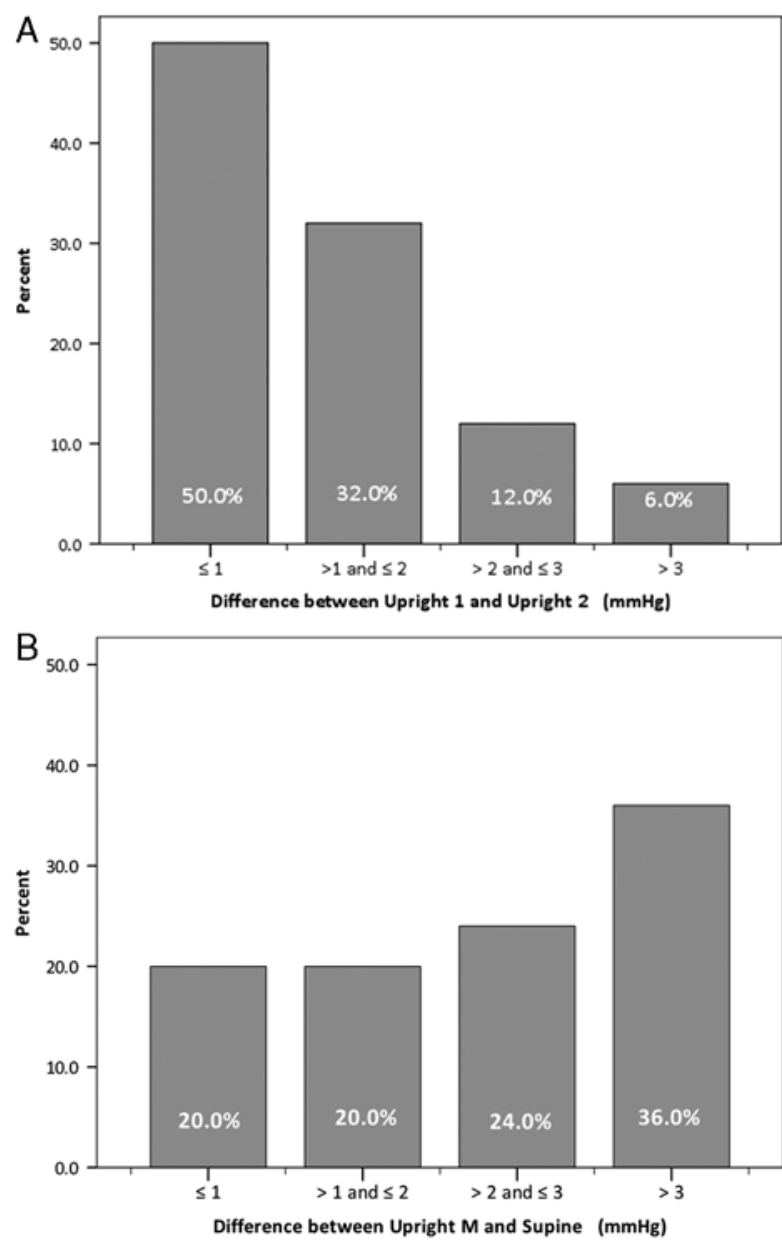

FIGURE 2. Frequency distribution of differences between both positions for: (A) upright position and (B) upright and supine position.

The Pulsair EasyEye is a portable air-puff tonometer that determines IOP in multiple positions and has proved to be reliable in the UP. ${ }^{17}$ Ogbuehi and Almubrad ${ }^{18}$ claimed that Pulsair EasyEye NCT is a useful method for monitoring IOP in the normotensive range, being a suitable alternative to the Goldmann applanation tonometer (GAT) for screening purposes, particularly in patients on whom it would be difficult or impossible to conduct a GAT. In their study, Babalola et $\mathrm{al}^{19}$ stated that, based on their findings, there was no significant difference in the mean IOP, as measured by GAT and NCT using the Keeler Pulsair EasyEye tonometer. However, in this literature, there are no results to confirm the repeatability of the Keeler Pulsair EasyEye tonometer when the air-puff is delivered in different positions. This results confirm earlier published ones and the Pulsair EasyEye tonometer presents a good repeatability in the UP.

Concerning the variations between the UP and the SUPs, there was a statistically significant increase in the IOP values of $2.47 \pm 2.12 \mathrm{~mm} \mathrm{Hg}$. Other publications have also reported this trend for tonometers with a different functioning principle. In 2006, Wozniak et $\mathrm{al}^{20}$ published the results of a research which used the Perkins contact tonometer in both healthy subjects and with primary openangle glaucoma patients. They concluded that the IOP measurement was higher in the SUP than in the UP and that there were no statistically significant differences in IOP changes between groups during diurnal IOP measurements in an UP. Conversely, in the SUP, IOP was significantly higher than in the UP, and increased more in the glaucoma patients than in healthy controls. The authors concluded that such observation might be because of a faulty regulation of the fluid shift in glaucoma patients and could cause the progression of glaucomatous damage.

In a article published in 2005, Garcia-Resua et $\mathrm{al}^{21}$ also verified an increase in the IOP values, when the measurements were obtained in the SUP, by comparison to the UP using a TGDc-01 tonometer. The obtained difference was of $0.42 \mathrm{~mm} \mathrm{Hg}$ with a larger SD when the measurements were obtained in the SUP (4.19 and $4.06 \mathrm{~mm}$ $\mathrm{Hg}$ in the SUP and UP, respectively). However, earlier reports identify several potential sources of error in this instrument and this could justify such results. ${ }^{22-24}$ This could explain the low difference obtained between the 2 positions, when compared with our results and results from other studies using more reliable tonometers.

Several studies have been developed concerning the IOP variation during 24 hours in normal populations, ${ }^{4,5,25-27}$ in glaucomatous patients ${ }^{28}$ and with different ages. $^{29}$ Although presenting a variation of the IOP mean values, those studies introduced a trend for IOP to increase in the SUP period during sleep. Nevertheless, the main concern is not the time usually spent in the SUP or prone position during the sleeping period. The causes for the IOP increase in the prone or SUP are still subject for discussion. Nevertheless, earlier studies have found that the IOP variation from postural change is because of an obstruction of the aqueous outflow provoked by an increase in the episcleral venous pressure. ${ }^{10}$

This issue might be much more important in people permanently bedridden, as well as those submitted to long surgical interventions and recovery times. For those people, there might be a higher risk of suffering ocular damage related to an IOP increase. ${ }^{14,30}$

In summary, results from this study have shown that IOP increases in the SUP, and that the Pulsar EasyEye tonometer is sensitive to those variations.

\section{ACKNOWLEDGMENTS}

The authors thank the work of Filomena Louro and Adriana Mesquita from the Scientific Editing Programme of Universidade do Minho for revising this article.

\section{REFERENCES}

1. Hara $T$, Hara $T$, Tsuru $T$. Increase of peak intraocular pressure during sleep in reproduced diurnal changes by posture. Arch Ophthalmol. 2006;124:165-168.

2. Syam PP, Mavrikakis I, Liu C. Importance of early morning intraocular pressure recording for measurement of diurnal variation of intraocular pressure. Br J Ophthalmol. 2005;89: 926-927.

3. Wilensky JT. Diurnal variations in intraocular pressure. Trans Am Ophthalmol Soc. 1991;89:757-790.

4. Ozcan MS, Praetel C, Bhatti MT, et al. The effect of body inclination during prone positioning on intraocular pressure in awake volunteers: a comparison of two operating tables. Anesth Analg. 2004;99:1152-1158; table. 
5. Perlman JI, Delany CM, Sothern RB, et al. Relationships between 24 hours observations in intraocular pressure versus blood pressure, heart rate, nitric oxide and age in the medical chronobiology aging project. Clin Ter. 2007;158:31-47.

6. Blondeau P, Tetrault JP, Papamarkakis C. Diurnal variation of episcleral venous pressure in healthy patients: a pilot study. J Glaucoma. 2001;10:18-24.

7. Buchanan RA, Williams TD. Intraocular pressure, ocular pulse pressure, and body position. Am J Optom Physiol Opt. 1985;62:59-62.

8. Longo A, Geiser MH, Riva CE. Posture changes and subfoveal choroidal blood flow. Invest Ophthalmol Vis Sci. 2004;45:546-551.

9. Singleton CD, Robertson D, Byrne DW, et al. Effect of posture on blood and intraocular pressures in multiple system atrophy, pure autonomic failure, and baroreflex failure. Circulation. 2003; 108:2349-2354.

10. Lam AK, Douthwaite WA. Does the change of anterior chamber depth or/and episcleral venous pressure cause intraocular pressure change in postural variation?. Optom Vis Sci. 1997;74:664-667.

11. Kiuchi T, Motoyama Y, Oshika T. Postural response of intraocular pressure and visual field damage in patients with untreated normal-tension glaucoma. J Glaucoma. 2009. Doi:10.1097/IJG.0b013e3181a98f30.

12. Spapen HD, D'Haese J, Diltoer M, et al. Bedside evaluation of intraocular pressure in critically ill patients, ventilated at different levels of positive end-expiratory pressure. Acta Anaesthesiol Belg. 1993;44:39-43.

13. Cheng MA, Todorov A, Tempelhoff R, et al. The effect of prone positioning on intraocular pressure in anesthetized patients. Anesthesiology. 2001;95:1351-1355.

14. Hunt K, Bajekal R, Calder I, et al. Changes in intraocular pressure in anesthetized prone patients. $J$ Neurosurg Anesthesiol. 2004;16:287-290.

15. Bland JM, Altman DG. Statistical methods for assessing agreement between two methods of clinical measurement. Lancet. 1986;1:307-310.

16. Bland JM, Altman DG. Comparing methods of measurement: why plotting difference against standard method is misleading. Lancet. 1995;346:1085-1087.

17. Kumar S, Middlemiss C, Bulsara M, et al. Telemedicine-friendly, portable tonometers: an evaluation for intraocular pressure screening. Clin Experiment Ophthalmol. 2006;34:666-670.

18. Ogbuehi KC, Almubrad TM. Accuracy and reliability of the Keeler Pulsair EasyEye non-contact tonometer. Optom Vis Sci. 2008;85:61-66.
19. Babalola OE, Kehinde AV, Iloegbunam AC, et al. A comparison of the Goldmann applanation and non-contact (Keeler Pulsair EasyEye) tonometers and the effect of central corneal thickness in indigenous African eyes. Ophthalmic Physiol Opt. 2009;29:182-188.

20. Wozniak K, Koller AU, Sporl E, et al. Intraocular pressure measurement during the day and night for glaucoma patients and normal controls using Goldmann and Perkins applanation tonometry. Ophthalmologe. 2006;103:1027-1031.

21. Garcia RC, Giraldez Fernandez MJ, Cervino EA, et al Clinical evaluation of the new TGDc- 01 "PRA" palpebral tonometer: comparison with contact and non-contact tonometry. Optom Vis Sci. 2005;82:143-150.

22. Losch A, Scheuerle A, Rupp V, et al. Transpalpebral measurement of intraocular pressure using the TGDc-01 tonometer versus standard Goldmann applanation tonometry. Graefes Arch Clin Exp Ophthalmol. 2005;243:313-316.

23. Lam AK, Lam $\mathrm{CH}$, Chan $\mathrm{R}$. The validity of a digital eyelid tonometer (TGDc-01) and its comparison with Goldmann applanation tonometry-a pilot study. Ophthalmic Physiol Opt. 2005;25:205-210.

24. Ruokonen PC, Schwenteck T, Draeger J. Evaluation of the impedance tonometers TGDc-01 and iCare according to the international ocular tonometer standards ISO 8612. Graefes Arch Clin Exp Ophthalmol. 2007;245:1259-1265.

25. Barkana Y, Anis S, Liebmann J, et al. Clinical utility of intraocular pressure monitoring outside of normal office hours in patients with glaucoma. Arch Ophthalmol. 2006;124: 793-797.

26. Liu JH, Kripke DF, Hoffman RE, et al. Elevation of human intraocular pressure at night under moderate illumination. Invest Ophthalmol Vis Sci. 1999;40:2439-2442.

27. Liu JH, Bouligny RP, Kripke DF, et al. Nocturnal elevation of intraocular pressure is detectable in the sitting position. Invest Ophthalmol Vis Sci. 2003;44:4439-4442.

28. Liu JH, Kripke DF, Weinreb RN. Comparison of the nocturnal effects of once-daily timolol and latanoprost on intraocular pressure. Am J Ophthalmol. 2004;138:389-395.

29. Liu JH, Kripke DF, Twa MD, et al. Twenty-four-hour pattern of intraocular pressure in the aging population. Invest Ophthalmol Vis Sci. 1999;40:2912-2917.

30. Walick KS, Kragh JE Jr, Ward JA, et al. Changes in intraocular pressure due to surgical positioning: studying potential risk for postoperative vision loss. Spine. 2007;32: $2591-2595$. 